\title{
Sodium-coupled monocarboxylate transporter is a target of epigenetic repression in cervical cancer
}

\author{
JENNIFER HERNÁNDEZ-JUÁREZ ${ }^{1}$, ORLANDO VARGAS-SIERRA ${ }^{1}$, LUIS A. HERRERA ${ }^{2}$, \\ DAVID CANTÚ DE LEÓN ${ }^{3}$, JORGE FERNÁNDEZ-RETANA ${ }^{2}$, CARLOS PÉREZ-PLASENCIA ${ }^{4}$, \\ CÉSAR LÓPEZ-CAMARILLO ${ }^{5}$, PATRICIO GARIGLIO ${ }^{1}$ and JOSÉ DÍAZ-CHÁVEZ ${ }^{2}$
}

\author{
${ }^{1}$ Department of Genetics and Molecular Biology, Centre for Research and Advanced Studies of the National \\ Polytechnic Institute, Mexico City 07360; ${ }^{2}$ Biomedical Unit for Cancer Research, Carcinogenesis Laboratory, Department of \\ Basic Research, Instituto de Investigaciones Biomédicas, UNAM/Instituto Nacional de Cancerologia (INCan); \\ ${ }^{3}$ Department of Gynaecological Oncology; ${ }^{4}$ Laboratory of Cancer Genomics, National Cancer Institute, Mexico City 14080; \\ ${ }^{5}$ Genomic Sciences Graduate Program, Autonomous University of Mexico City, Mexico City 03100, Mexico
}

Received October 22, 2018; Accepted February 11, 2019

DOI: $10.3892 /$ ijo.2019.4749

\begin{abstract}
The SLC5A8 gene encodes Na monocarboxylate transporter 1 , which is epigenetically inactivated in various tumour types. This has been attributed to the fact that it prevents the entry of histone deacetylase (HDAC) inhibitors and favours the metabolic reprogramming of neoplastic cells. Nevertheless, its expression and regulation in cervical cancer (CC) have not been elucidated to date. The aim of the present study was to investigate whether SLC5A8 expression is silenced in $\mathrm{CC}$ and if epigenetic mechanisms are involved in its regulation. Using RNA and DNA from human CC cell lines and tumour tissues from patients with $\mathrm{CC}$, the expression of SLC5A8 was analysed by reverse transcription polymerase chain reaction and the methylation status of its $\mathrm{CpG}$ island (CGI) by bisulphite-modified sequencing.
\end{abstract}

Correspondence to: Dr José Díaz-Chávez, Cancer Biomedical Research Unit, Instituto de Investigaciones Biomédicas, UNAM/ Instituto Nacional de Cancerologia (INCan), 22 San Fernando Avenue, Mexico City, 14080, México.

E-mail: josediaz030178@hotmail.com

Dr Patricio Gariglio, Department of Genetics and Molecular Biology, Centre for Research and Advanced Studies of the National Polytechnic Institute, 2508 Avenida Instituto Politécnico Nacional, Mexico City 07360, Mexico

E-mail: vidal@cinvestav.mx

Abbreviations: CC, cervical cancer; CGI, CpG island; TT, tumour tissue; DNMT, DNA methyltransferase; 5-azadC, 5-aza-2'-deoxycytidine; TSA, trichostatin A; TSG, tumour suppressor gene; HDAC, histone deacetylase; MS-PCR, methylation-specific polymerase chain reaction; NCT, non-tumour cervical tissue, M-SLC5A8, methylated SLC5A8; U-SLC5A8, unmethylated SLC5A8

Key words: SLC5A8, epigenetics, DNA methylation, CpG island, silencing and cervical cancer
Additionally, SLC5A8 reactivation was examined in the CC cell lines following treatment with DNA methylation (5-aza-2'-deoxycytidine) and HDAC inhibitors (trichostatin A and pyruvate). All the $\mathrm{CC}$ cell lines and a range of tumour tissues (65.5\%) exhibited complete or partial loss of SLC5A8 transcription. The bisulphite-sequencing revealed that hypermethylation of the CGI within SLC5A8 first exon was associated with its downregulation in the majority of cases. The transporter expression was restored in the CC cell lines following exposure to 5-aza-2'-deoxycytidine alone, or in combination with trichostatin A or pyruvate, suggesting that DNA methylation and histone deacetylation contribute to its inhibition in a cell line-dependent manner. Together, the results of the present study demonstrate the key role of DNA hypermethylation in the repression of SLC5A8 in CC, as well as the involvement of histone deacetylation, at least partially. This allows for research focused on the potential function of SLC5A8 as a tumour suppressor in CC, and as a biomarker or therapeutic target in this malignancy.

\section{Introduction}

Cervical cancer (CC) is a common malignancy among women worldwide. According to the Global Cancer Incidence, Mortality and Prevalence 2018 surveillance data, the estimated incidence rate is 570,000 new cases per year worldwide, although the majority occur in developing countries (1). Persistent infection with high-risk human papillomavirus (HR-HPV) serves a crucial aetiological role in this disease. Nevertheless, HPV alone is not sufficient to trigger malignancy. Additional genetic events and environmental cofactors are required for the development of CC (2). Likewise, epigenetic alterations contribute to aberrant gene expression or function during each stage of the tumourigenic process (3).

The most characterized epigenetic mark is DNA methylation at the cytosine of $\mathrm{CpG}$ dinucleotides, followed by modifications of histone proteins that mediate the packaging 
of DNA into chromatin. The interplay of these mechanisms regulates gene expression through controlling chromatin conformation (4). Under normal conditions, $\mathrm{CpG}$ methylation is observed over repetitive elements to prevent chromosomal instability and over $\mathrm{CpG}$ islands (CGIs) associated with the 5 ' region of certain genes, switching off their expression when not required, e.g. for X-chromosome inactivation in females, or for transcriptional silencing of tissue-specific genes. Aside from that, deregulated $\mathrm{CpG}$ methylation has been described in diverse disease states, including cancer (5). The CGIs in or near promoters of multiple tumour suppressor genes (TSGs) gain a high density of de novo methylation, leading to their improper transcriptional silencing and consequently contributing to carcinogenesis (6). Hence, there is a growing effort in defining the genes affected by this mechanism in cancer research, and our interest lies in identifying potential molecular targets for treatment of $\mathrm{CC}$ and/or potential biomarkers for the diagnosis and prognosis of this disease.

The idea that plasma membrane transporters can also function as tumour suppressors has received little attention in cancer (7). Despite this, $\mathrm{Na}^{+}$-coupled monocarboxylate transporter 1 (SLC5A8) was identified as a TSG in colon cancer (8) and its silencing is a recognised characteristic of other cancers (9-11), yet, to the best of our knowledge, no studies exist regarding its expression in CC. SLC5A8 is a $\mathrm{Na}^{+}$-coupled co-transporter for monocarboxylates, including short-chain fatty acids, such as propionate and butyrate, as well as pyruvate, all of which are known to inhibit histone deacetylases (HDACs) $(7,10,11)$. Certain studies have documented that the transporter silencing is caused by hypermethylation of the CGI around its promoter, and that restoration of its expression leads to cell growth suppression associated with its ability to import the aforementioned HDAC inhibitors $(8,12)$. In contrast, lactate, which is another substrate of SLC5A8, does not inhibit HDACs $(11,13,14)$. Since the kinetics of SLC5A8 favour the import of this metabolite instead of its export, neoplastic cells, which already generate excessive lactate by glycolysis, may also suppress the expression of this transporter to counteract the high levels of acidity that can have harmful consequences for these cells $(11,13-15)$.

Upon HR-HPV infection, viral E6 and E7 oncoproteins induce the expression of DNA methyltransferases (DNMTs) and modulate the activity of histone modification enzymes, as well as chromatin remodelling enzymes $(16,17)$, resulting in the silencing of TSGs and the expression of oncogenes. Given that SLC5A8 epigenetic inactivation contributes to carcinogenesis and tumour progression, the aim of this study was to investigate whether SLC5A8 expression is silenced in CC. It was revealed that SLC5A8 is transcriptionally inhibited in CC cell lines and tumour tissues (TTs). The abnormal DNA methylation patterns of the SLC5A8 CGI were characterized and its methylation status was measured. Furthermore, the epigenetic reactivation of SLC5A8 expression in CC cell lines was demonstrated by pharmacological inhibition of DNA methylation and histone deacetylation. Collectively, the present results demonstrate that the repression of SLC5A8 is a common event in this malignancy and highlight a clear association between DNA hypermethylation and loss of SLC5A8 expression.

\section{Materials and methods}

Cell lines. Five human CC cell lines (HeLa, CaLo, $\mathrm{SiHa}$, CaSki and C-33A) were used for SLC5A8 expression assays and DNA methylation analyses. Embryonic kidney 293 and colorectal cancer HCT116 cell lines were used as positive and negative controls of expression, respectively. All cell lines were obtained from the American Type Culture Collection (Manassas, VA, USA), except for CaLo, which was a gift from B. Weiss-Steider (Molecular Oncology Laboratory, Cell Differentiation and Cancer Research Unit, Faculty of Higher Studies Zaragoza, National Autonomous University of Mexico, Mexico City, Mexico). The cells were cultured in Dulbecco's modified Eagle's medium (Thermo Fisher Scientific, Inc. Waltham, MA, USA), supplemented with $10 \%$ fetal bovine serum and $1 \%$ penicillin/streptomycin, in a humidified $5 \% \mathrm{CO}_{2}$ incubator at $37^{\circ} \mathrm{C}$.

Human cervical tissue specimens. The human tissue samples analysed in this study $(\mathrm{n}=30)$ were obtained from patients under cervical tumour banking protocols (April 2010-August 2012). Approval was obtained from the Institutional Ethics and Scientific Board Committees at the National Cancer Institute of Mexico. The TTs came from female patients diagnosed with primary CC aged 20-60 years, who signed an informed consent form. All tumours were confirmed by clinical pathological examination previous to this study at the Department of Pathology of the National Cancer Institute (Mexico City, Mexico). The staging criteria for cervical cancer were in accordance with the FIGO (International Federation of Gynaecology and Obstetrics) guidelines $(18,19)$. The sample eligibility criteria were: Patients with a confirmed pathologic diagnosis of FIGO stage IB2-IIIB CC, biopsies with $>80 \%$ tumour cells, and cases with no previous oncological treatment. TTs were obtained from punch biopsies $(3-5 \mathrm{~mm}$ in diameter). Each biopsy sample was split into 3 sections: One for pathological confirmation, one for RNA extraction, and one for DNA isolation. The sections destined for nucleic acid extraction were snap-frozen in liquid nitrogen and stored at $-70^{\circ} \mathrm{C}$. Additionally, 6 non-tumour cervical epithelial tissues (NCTs) were collected from patients who had originally presented with abnormal cervical screening, but in further tests were not diagnosed with cervical cancer.

DNA extraction from patient samples and HPV genotyping. DNA was isolated from cervical tumour biopsy samples with a MagNAPure Compact instrument (Roche Diagnostics GmbH, Mannheim, Germany), according to the manufacturer's instructions. HPV genotypes were evaluated using the Roche Linear Array HPV Genotyping test (Roche Diagnostics $\mathrm{GmbH}$ ) and by an MY/GP nested multiplex polymerase chain reaction (PCR) with subsequent PCR fragment direct sequencing, as previously described by Sotlar et al (20).

RNA extraction. Total RNA was obtained from harvested cells or frozen ground tissues using TRIzol reagent (Invitrogen; Thermo Fisher Scientific, Inc.). The extraction was performed as per the manufacturer's protocol. All samples underwent treatment with DNase I (Ambion; Thermo Fisher Scientific, Inc.). RNA purity and concentration were measured using a NanoDrop ${ }^{\mathrm{TM}}$ ND-8000 spectrophotometer (Thermo Fisher 
Table I. Sequences of the primers used for RT-PCR, MS-PCR and bisulphite-modified sequencing.

\begin{tabular}{|c|c|c|}
\hline Primer name & Sequence & Amplicon size, bp \\
\hline SLC5A8 & $\begin{array}{l}\text { F: 5'-TCCGAGGTCTACCGTTTTG-3' } \\
\text { R: 5'-GGGCAGGGGCATAAATAAC-3' }\end{array}$ & 229 \\
\hline$\beta 2 \mathrm{M}$ & $\begin{array}{l}\text { F: 5'-GGACTGGTCTTTCTATCTCTTGT-3' } \\
\text { R: 5'-ACCTCCATGATGCTGCTTAC-3' }\end{array}$ & 100 \\
\hline M-SLC5A8 & $\begin{array}{l}\text { F: 5'-TTCGGTCGTTATCGGTATTTATTAC-3' } \\
\text { R: 5'-CGAACACTACGATCATTCTACGA-3' }\end{array}$ & 100 \\
\hline U-SLC5A8 & $\begin{array}{l}\text { F: 5'-TTTGGTTGTTATTGGTATTTATTATGT-3' } \\
\text { R: 5'-CCACAAACACTACAATCATTCTACAA-3' }\end{array}$ & 98 \\
\hline bsSLC5A8 & $\begin{array}{l}\text { F: 5'-GAGGTTTTATATTTGGGTTTGAGG-3' } \\
\text { R: 5'-CCCATCAAAAAATCCTTAAAAATCTA-3' }\end{array}$ & 379 \\
\hline
\end{tabular}

RT-PCR, reverse transcription polymerase chain reaction; MS-PCR, methylation-specific polymerase chain reaction; SLC5 A8, Na ${ }^{-}$-coupled monocarboxylate transporter 1; $\beta 2 \mathrm{M}, \beta-2$ microglobulin; M-SLC5A8, methylated SLC5A8; U-SLC5A8, unmethylated SLC5A8; bsSLC5A8, bisulphite-modified SLC5A8; F, forward; R, reverse.

Scientific, Inc., Wilmington, DE, USA). Additionally, RNA integrity was assessed by electrophoresis on a $1.2 \%$ agarose gel, by resolving the $28 \mathrm{~S}$ and $18 \mathrm{~S}$ ribosomal RNA bands. The samples were stored at $-70^{\circ} \mathrm{C}$ until further use.

cDNA synthesis and PCR. Total RNA was reverse transcribed into cDNA using the Murine Leukemia Virus Reverse Transcriptase of the RevertAid First Strand cDNA Synthesis kit (Thermo Fisher Scientific, Inc.), at $45^{\circ} \mathrm{C}$ for $60 \mathrm{~min}$ and $70^{\circ} \mathrm{C}$ for $5 \mathrm{~min}$, according to the manufacturer's instructions. Subsequently, semi-quantitative PCR reactions were performed using Platinum ${ }^{\mathrm{TM}}$ Taq polymerase (Invitrogen; Thermo Fisher Scientific, Inc.). SLC5A8 amplified fragment extends from the terminal portion of exon 1 to exon 2 , encompassing a 229-bp region. The thermocycling conditions were as follows: Initial denaturation at $95^{\circ} \mathrm{C}$ for $5 \mathrm{~min}$, followed by 40 cycles of $95^{\circ} \mathrm{C}$ for $30 \mathrm{sec}, 56.4^{\circ} \mathrm{C}$ for $30 \mathrm{sec}$ and $72^{\circ} \mathrm{C}$ for $30 \mathrm{sec}$, and a final extension step at $72^{\circ} \mathrm{C}$ for $10 \mathrm{~min} . \beta-2$ microglobulin was used to assess the quality (integrity and concentration) of cDNA under the same amplification conditions, with the exception of the annealing temperature $\left(60^{\circ} \mathrm{C}\right)$ and the number of amplification cycles (30 cycles). Following amplification, the PCR products were analysed by $1.8 \%$ agarose gel electrophoresis and the products were visualized by ethidium bromide staining. The full list of primers is included in Table I.

In order to assess the relative expression of SLC5A8 among the TTs, the cDNA was assayed and normalized against $\beta-2$ microglobulin under the same thermocycling conditions mentioned above (30 cycles for both). The PCR products were analysed by $1.8 \%$ agarose gel electrophoresis by ethidium bromide staining. Images were acquired with GeneSnap version 7.02 software (Syngene Europe, Cambridge, UK) and the band intensities were measured with ImageJ software version 1.46 (National Institutes of Health, Bethesda, MD, USA). The samples that exhibited undetectable SLC5A8 were set as the negative reference. The ratio between SLC5A8 and $\beta-2$ microglobulin intensity was determined for each sample, with values ranging from 0 to 1 . The SLC5A8 expression classification was based on the following threshold values: 0 , null; 0.25 , low; 0.5 , medium; and 1 , high.

DNA isolation and sodium bisulphite modification assay. Genomic DNA was isolated from cells using the Wizard Genomic DNA Purification kit (Promega Corporation, Madison, WI, USA), as per the manufacturer's protocol. The DNA concentration and integrity were assessed by absorbance measurements and agarose gel electrophoresis. Following isolation, the genomic DNA from the cells and tissues was bisulphite-modified using the EZ DNA methylation kit (Zymo Research Corp., Irvine, CA, USA). The modified DNA was kept at $-20^{\circ} \mathrm{C}$ until further use in PCR amplification processes for detecting methylation.

Methylation-specific PCR (MS-PCR). MS-PCR was used as a quick assessment of whether SLC5A8 is target of methylation in CC cell lines. Initially, the SLC5A8 gene sequence was introduced into the EMBOSS CpGplot (http://www.ebi. ac.uk/Tools/seqstats/emboss_cpgplot/) and the Methprimer software (www.urogene.org/methprimer) to search for potential CGIs and to obtain two primer pairs specific for binding either methylated (M-SLC5A8) or unmethylated (U-SLC5A8) bisulphite-converted DNA. Independent PCRs were performed with each set of primers (Table I) using the Platinum Taq polymerase. The amplification conditions were as follows: Initial denaturation at $94^{\circ} \mathrm{C}$ for $5 \mathrm{~min}$, followed by 40 cycles of $94^{\circ} \mathrm{C}$ for $45 \mathrm{sec}, 56^{\circ} \mathrm{C}$ for $45 \mathrm{sec}$ and $72^{\circ} \mathrm{C}$ for $45 \mathrm{sec}$, and a final extension step at $72^{\circ} \mathrm{C}$ for $10 \mathrm{~min}$. DNA from HCT116 and 293 cells was included as the methylated and unmethylated controls, respectively. Following amplification, the PCR products were analysed by $1.8 \%$ agarose gel electrophoresis.

Bisulphite-sequencing analysis. Sequencing analysis of bisulphite-treated DNA was used to determine the methylation density of a 379-bp region within the SLC5A8 CGI. The primers for targeting the bisulphite-modified sequence of SLC5A8 are listed in Table I and the PCR thermocycling conditions were: 


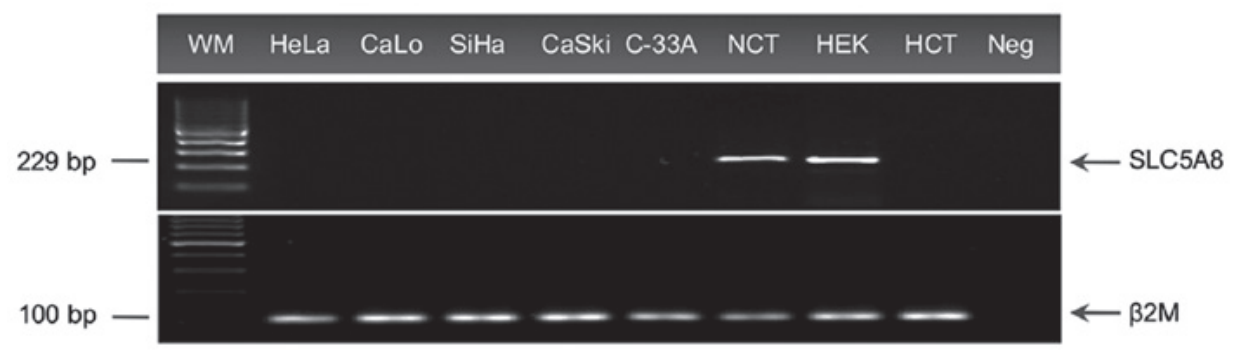

Figure 1. SLC5A8 mRNA levels are undetected in human cervical cancer cell lines compared with NCT samples. SLC5A8 mRNA expression (top) was detected in representative cervical cancer cell lines (HeLa, CaLo, SiHa, CaSki and C-33A) and NCTs by reverse transcription and polymerase chain reaction analysis. The expression of $32 \mathrm{M}$ (bottom) was used as endogenous reference control. HEK and HCT were used as positive and negative controls of SLC5A8 expression, respectively. SLC5A8, $\mathrm{Na}^{+}$-coupled monocarboxylate transporter 1; NCT, non-tumour cervical tissue; $\beta 2 \mathrm{M}, \beta-2$ microglobulin; HEK, 293 cells; HCT, HCT116 cells; WM, weight marker; Neg, no template control.

Initial denaturation at $95^{\circ} \mathrm{C}$ for $5 \mathrm{~min}$, followed by 40 cycles of $95^{\circ} \mathrm{C}$ for $45 \mathrm{sec}, 61^{\circ} \mathrm{C}$ for $60 \mathrm{sec}$ and $72^{\circ} \mathrm{C}$ for $45 \mathrm{sec}$, and a final extension step at $72^{\circ} \mathrm{C}$ for $10 \mathrm{~min}$. The PCR products were verified by $1.5 \%$ agarose gel electrophoresis. Successful amplification products were immediately purified using the QIAquick PCR Purification kit (Qiagen GmbH, Hilden, Germany), ligated to the pJet1.2 vector using the CloneJET PCR cloning kit (Thermo Fisher Scientific, Inc.) and transformed into competent DH5 $\alpha$ bacteria. The transformed bacteria were plated on agar containing selective media. For each sample, 3-5 random colonies carrying the target DNA were selected and grown in lysogeny broth medium (Invitrogen; Thermo Fisher Scientific, Inc.). The plasmids were extracted with the QIAprep Spin Miniprep kit (Qiagen GmbH), and the DNA was sequenced using a BigDye Terminator v3.1 Cycle Sequencing kit and an ABI PRISM ${ }^{\circledR} 310$ Genetic Analyzer (both from Thermo Fisher Scientific, Inc.). The BiQ Analyzer software version 2.0 (21) was used for processing the DNA methylation data and generating the $\mathrm{CpG}$ methylation diagrams .

Measurement of global methylation. To calculate the global CpG methylation, a score was assigned to each site, in terms of the number of methylated and unmethylated cytosines at a given position, considering the total alleles analysed from each sample. The score was assigned as follows: Uniformly methylated (m)CpG site, 2; uniformly unmethylated CpG site, 0 ; semimethylated $\mathrm{CpG}$ site, predominantly methylated, 1.5; and semimethylated $\mathrm{CpG}$ site, predominantly unmethylated, 0.5. The score of each CpG site was added and divided by 90 (total number of analysed sites $\mathrm{x}$ maximum score $=45 \times 2$ ), and the result was multiplied by 100 .

Measurement of $\mathrm{mCp} G$ density. Based on the total sequenced clones, a $\mathrm{CpG}$ site was considered to be methylated when the number of alleles exhibiting methylation at that position was greater than the number of unmethylated alleles. The density of $\mathrm{mCpG}$ sites in the sequenced region was calculated as follows: Number of $\mathrm{mCpGs}$ x 100/total number of CpGs sampled (45 sites).

In vitro demethylation and HDAC inhibition in CC cells. Stock solutions of $100 \mathrm{mM}$ 5-aza-2'-deoxycytidine (5-azadC) and $1 \mathrm{mM}$ trichostatin A (TSA) (both from Sigma-Aldrich; Merck KGaA, Darmstadt, Germany) were prepared by dissolving the reagents in dimethylsulphoxide (DMSO) for cellular treatments. The cells were seeded and allowed to recover overnight. Subsequently, 5-azadC was added to the complete growth medium at a final concentration of either $10 \mu \mathrm{M}$ (HeLa, SiHa and CaSki cells) or $20 \mu \mathrm{M}$ (CaLo and C-33A cells). Mock-treated cells with DMSO were used as controls. Cell culture medium containing fresh 5 -azadC or DMSO was changed every $24 \mathrm{~h}$ for 4 days. Cells cultured with or without 5 -azadC were treated for $24 \mathrm{~h}$ with $0.8 \mu \mathrm{M}$ TSA (final concentration) on day 5. The same experimental conditions were run with $1 \mathrm{mM}$ pyruvate (Gibco; Thermo Fisher Scientific, Inc.) added to the growth medium. The cells were harvested following the treatments and RNA was extracted for reverse transcription (RT)-PCR analysis as described above.

Statistical analysis. Differences in the $\mathrm{mCpG}$ density among the NCT and TT clusters with different SLC5A8 expression levels were evaluated by a Kruskal-Wallis test with Dunn's post hoc analysis, using the GraphPad Prism software programme, version 6.00 (GraphPad Software, Inc., La Jolla, CA, USA). Differences with $\mathrm{P}<0.01$ were considered to be statistically significant.

\section{Results}

SLC5A8 expression is repressed in human CC cell lines. The present study aimed to characterize the expression of SLC5A8 in CC. Hence, 5 CC cell lines (HeLa, CaLo, SiHa, CaSki and C-33A) along with NCTs, were analysed by semi-quantitative RT-PCR. Additionally, the embryonic kidney 293 and colon cancer HCT116 cells were used as positive and negative controls of SLC5A8 expression, respectively. As demonstrated in Fig. 1, the SLC5A8 transcript was detected in the NCT. In contrast, SLC5A8 was not detected in any of the analysed CC cells.

SLC5A8 is epigenetically silenced in CC cell lines. Given that aberrant DNA methylation has been identified to be responsible for the repression of SLC5A8 in various types of cancer, this prompted the question of whether this epigenetic regulation is occurring in CC. To this end, an in silico analysis was performed to determine the precise CGI location. According to the EMBOSS CpGplot software, using the criteria of $>50 \% \mathrm{CpG}$ content and a ratio of observed/expected CpG >0.6, SLC5A8 was revealed to contain a dense CGI spanning 576 bp in exon 1 (Fig. 2A). The identified CGI 


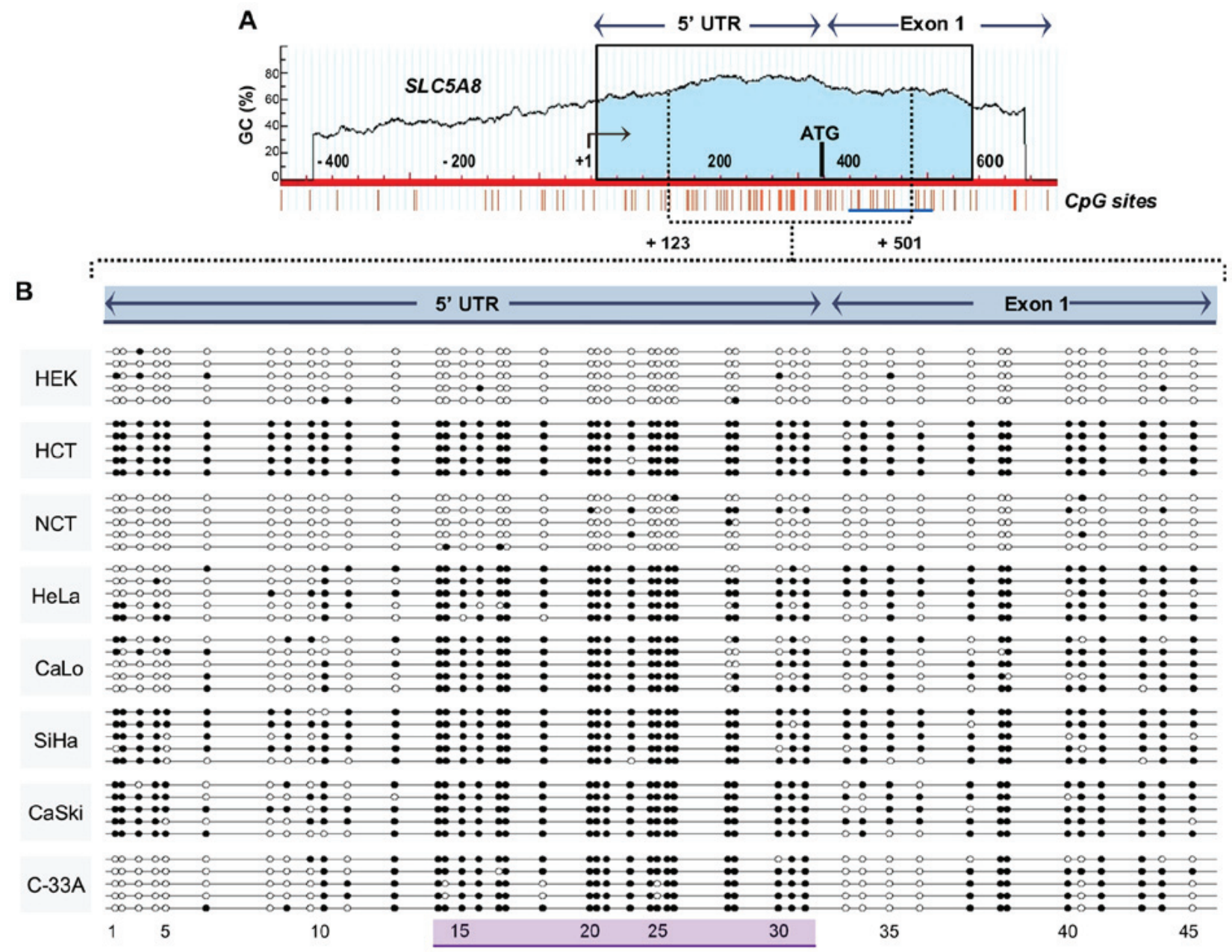

Figure 2. Aberrant SLC5A8 methylation in cervical cancer cell lines is confirmed by bisulphite-sequencing. (A) Diagram of the SLC5A8 gene promoter/first exon region. In silico analyses were used to predict CGIs in SLC5A8, using EMBOSS CpGplot and Methprimer software. The predicted CGI spans a 576-bp region within the first exon (blue shaded area). It is located at the range of +12 to +587 bp from the transcriptional start site (the +1 nucleotide position is indicated by the right-angled arrow according to the Eukaryotic Promoter Database). The thin vertical red lines under the plot represent the location of each $\mathrm{CpG}$ site. The area indicated by the dotted line is the selected region for bisulphite-sequencing analysis (nucleotides +123 to +501 ). The segment analysed by methylation-specific polymerase chain reaction is indicated by the horizontal blue line below the respective $\mathrm{CpG}$ sites. (B) The sequenced region representing the methylation status of the 45 examined CpG sites (379-bp region) in non-SLC5A8 expressing cell lines (HeLa, CaLo, SiHa, CaSki and C-33A) and NCTs. HEK and HCT were used as unmethylated and methylated controls, respectively. Each row represents the profile of a single sequenced clone (5 clones per sample). Each circle indicates an individual $\mathrm{CpG}$ site; white represents unmethylated and black represents methylated sites. The purple horizontal bar at the bottom of the panel indicates a string of almost uniformly methylated $\mathrm{CpG}$ sites in all the cervical cancer cell lines. The CpG sites are numbered in 5'-3' order and the distance separating them represents the relative number of nucleotides between them. SLC5A8, $\mathrm{Na}^{+}$-coupled monocarboxylate transporter 1; CGI, CpG island; NCT, non-tumour cervical tissue; HEK, 293 cells; HCT, HCT116 cells; UTR, untranslated region.

comprises the 5'-untranslated region (5'-UTR) and the beginning of the coding region, from nucleotide position +12 to +587 relative to the transcriptional start site (TSS) annotated on the Eukaryotic Promoter Database (http://epd.epfl. ch/human/human_database.php?db=human), using accession nos. SLC5A8 or NM_145913. Based on this result and using the Methprimer software, a 100-bp subregion (between nucleotides +430 and +530 ) was selected to determine whether DNA methylation was implicated in the downregulation of SLC5A8. The presence of methylation in $7 \mathrm{CpG}$ dinucleotides along the primer binding sites was assessed by MS-PCR analysis, using genomic DNA that was previously modified by bisulphite treatment for the selective conversion of cytosines to uracil, without affecting the 5-methylcytosines (22). HCT116 cells, known to contain a fully M-SLC5A8, were used as a positive control for methylation, and 293 cells were used as a negative control. This screening detected methylated $\mathrm{CpG}$ sites within the SLC5A8 CGI in the 5 analysed CC cell lines, as well as in the NCTs. However, the CC cell lines displayed a preferential amplification of the M-SLC5A8 allele, whereas the U-SLC5A8 allele was amplified to a greater extent in the NCTs (Fig. S1). Based on these results, it is feasible that the predominant amplification of the methylated allele in the $\mathrm{CC}$ cell lines is associated with the absence of SLC5A8 gene expression.

Next, bisulphite-sequencing analysis was conducted to explore whether methylation was limited to a few $\mathrm{CpG}$ sites, or if most of the SLC5A8 CGI was hypermethylated. A 379-bp target region was selected for evaluating the precise methylation status of $45 \mathrm{CpG}$ sites in individually cloned DNA molecules (Fig. 2A). In the diagram of the bottom panel (Fig. 2B), each row reflects the epigenetic profile of an allele (epigenotype). The 293 and HCT116 cells were included as unmethylated and methylated controls, respectively. The 


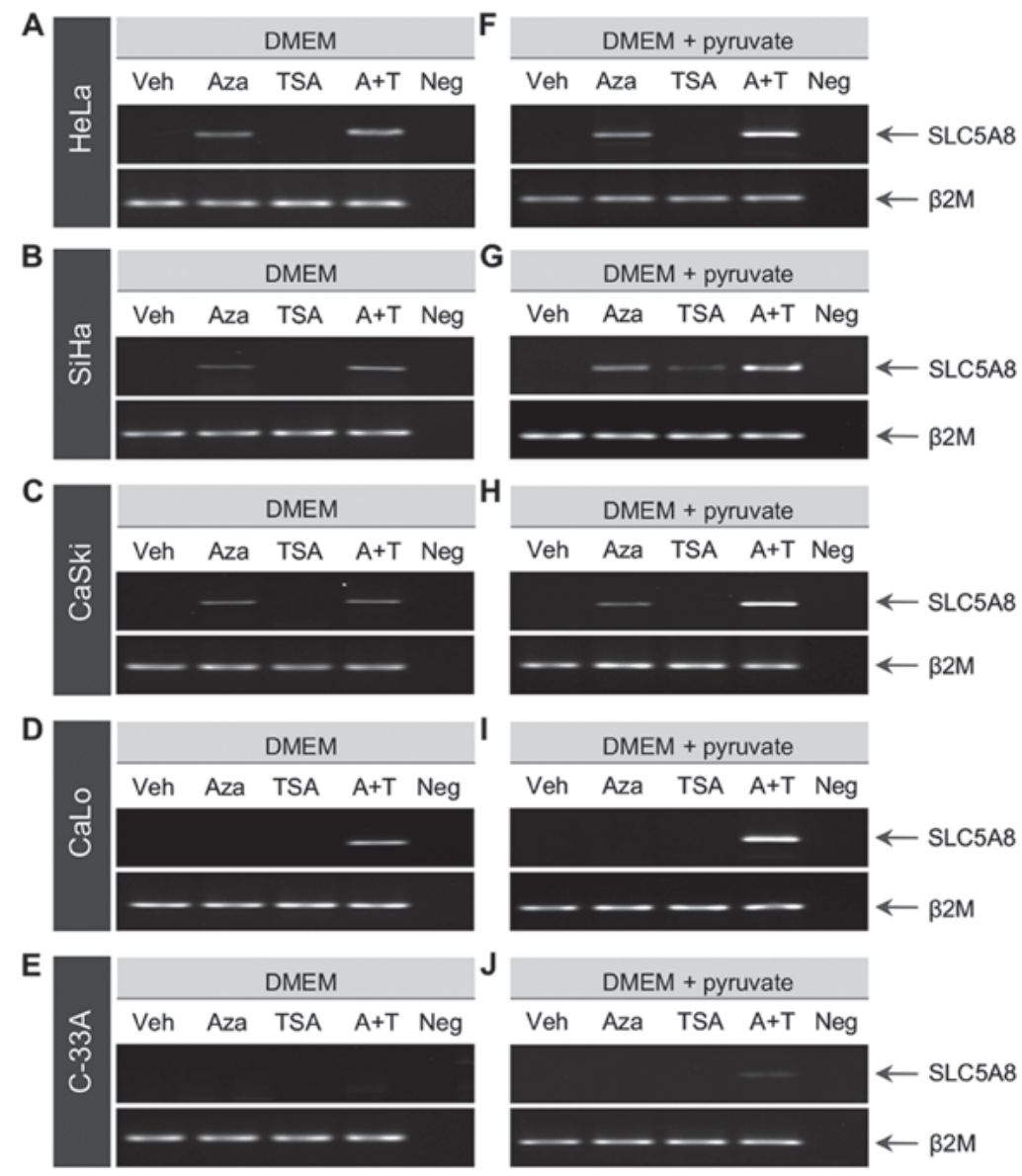

Figure 3. SLC5A8 expression in cervical cancer cell lines is reactivated in response to epigenetic drugs targeting DNA methylation and histone deacetylation enzymes. Reverse transcription polymerase chain reaction results of SLC5A8 (top) and $\beta 2 \mathrm{M}$ (bottom) transcripts from cervical cancer (A) HeLa (B) SiHa and (C) CaSki cells treated with $10 \mu \mathrm{M}$ Aza or (D) CaLo and (E) C-33A cells treated with $20 \mu \mathrm{M}$ Aza for 4 days, $0.8 \mu \mathrm{M}$ TSA (1 day), and the combination A+T, in DMEM. (F-J) Similar to the above, but in the presence of $1 \mathrm{mM}$ pyruvate. The expression of $\beta 2 \mathrm{M}$ was used as an endogenous reference control. SLC5A8, $\mathrm{Na}^{+}$-coupled monocarboxylate transporter 1; $\beta 2 \mathrm{M}, \beta-2$ microglobulin; Aza, 5-aza-2'-deoxycytidine; TSA, trichostatin A; A+T, 5-aza-2'-deoxycytidine and trichostatin A; DMEM, Dulbecco's modified Eagle's medium; Veh, vehicle-treated cells; Neg, no template control.

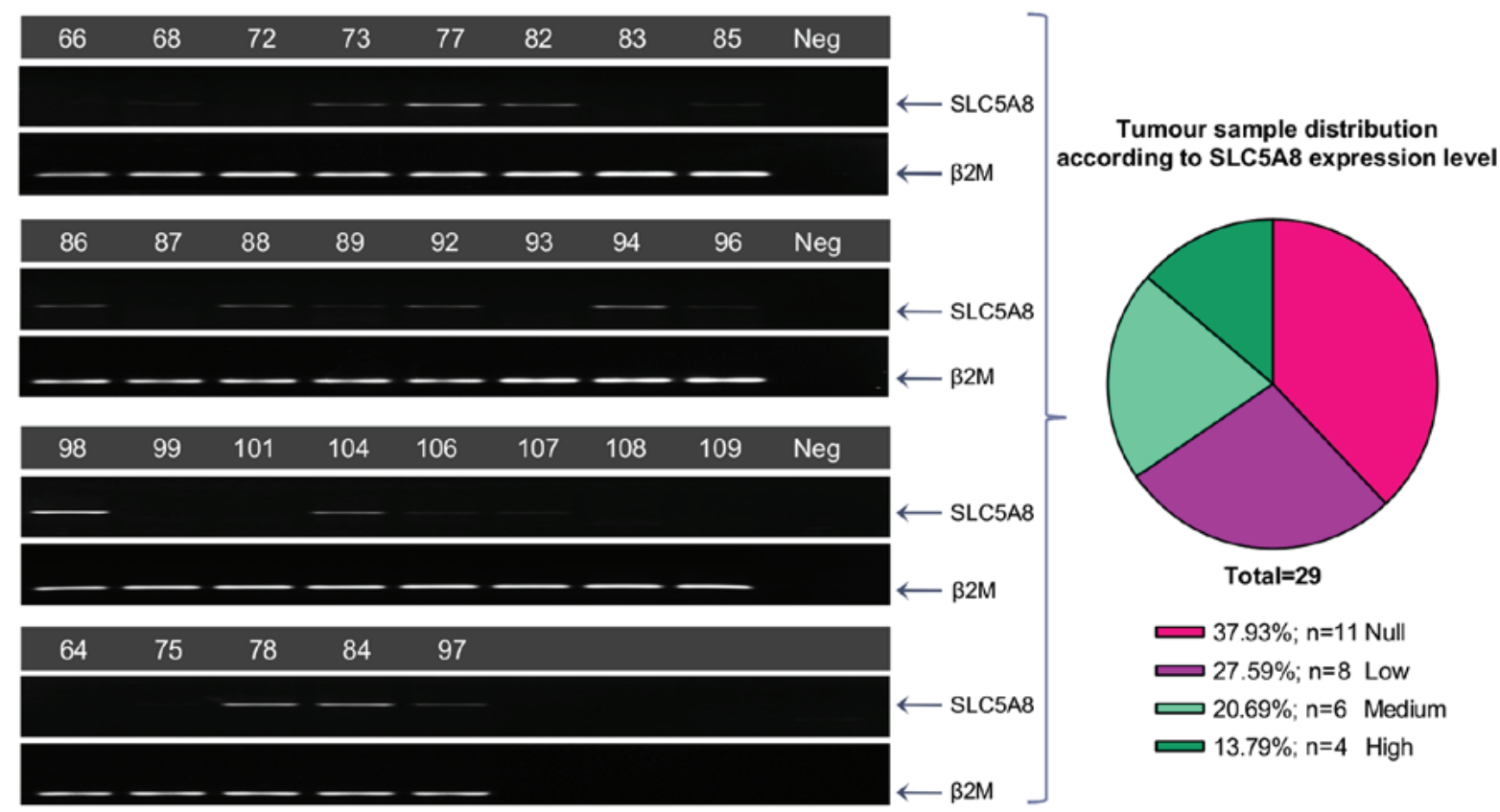

Figure 4. Analysis of SLC5A8 expression levels in patients with cervical cancer. SLC5A8 expression, determined by reverse transcription and semi-quantitative polymerase chain reaction analysis, in a panel of 29 samples from patients with cervical cancer. $\beta 2 \mathrm{M}$ expression was used as an endogenous reference control. On the right, the pie chart displays the distribution of the tumour samples, according to the level of SLC5A8 expression. SLC5A8, Na ${ }^{+}$-coupled monocarboxylate transporter $1 ; \beta 2 \mathrm{M}, \beta-2$ microglobulin; Neg, no template control. 
A

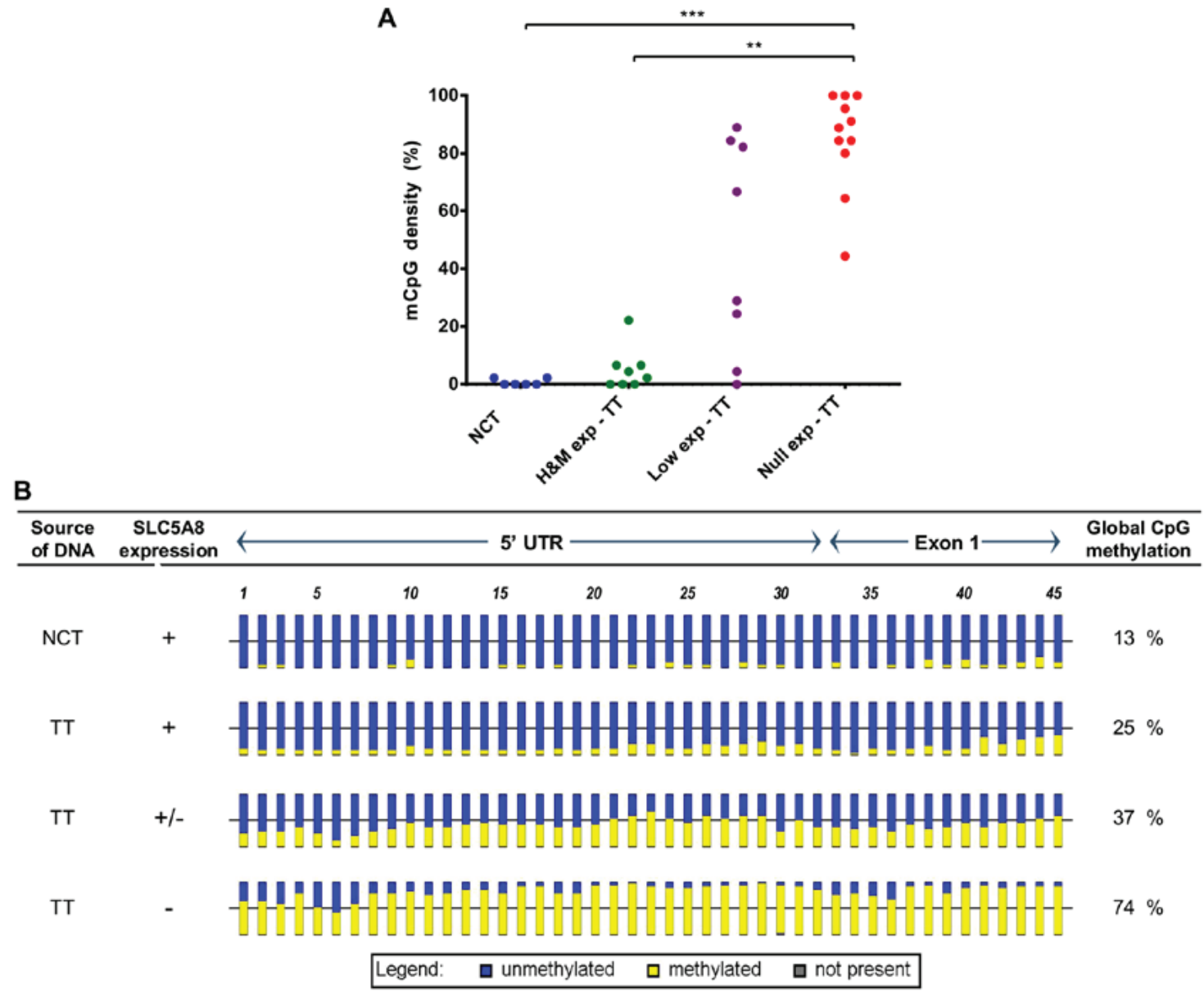

B

Figure 5. SLC5A8 expression is associated with first exon DNA hypermethylation in cervical cancer tissues. (A) Plot of the density of $\mathrm{mCpG}$ sites along the SLC5A8 CGI in cervical cancer samples from individual patients. The $\mathrm{mCpG}$ density was calculated from the data of 3-4 sequenced clones for each sample. The categories of the TTs $(\mathrm{n}=27)$ were based on their SLC5A8 mRNA expression levels (high and medium expression, $\mathrm{n}=8$; low expression, $\mathrm{n}=8$; and null expression, $\mathrm{n}=11$ ). Additionally, 6 NCT samples were used as references. ${ }^{* *} \mathrm{P}<0.01$ and ${ }^{* * * *} \mathrm{P}<0.001$. (B) Diagram summarising the bisulphite-sequencing results of the SLC5A8 CGI in TTs and NCTs, generated by BiQ Analyzer software. Each row represents the methylation profiles of all the clones in each cluster (+, high and medium SLC5A8 expression; +/-, low expression; -, undetectable expression). The boxes represent each of the CpG sites analysed and the colour ratio corresponds to the proportion of methylated and unmethylated sites at that position. The colour code and score were assigned as follows: Uniformly mCpG site (yellow box; score, 2), uniformly unmethylated $\mathrm{CpG}$ site (blue box; score, 0 ), semimethylated $\mathrm{CpG}$ site, predominantly methylated (mainly yellow box; score, 1.5), and semimethylated CpG site, predominantly unmethylated (mainly blue box; score, 0.5 ). SLC5A8, $\mathrm{Na}^{+}$-coupled monocarboxylate transporter 1; mCpG, methylated CpG; CGI, CpG island; TT, tumour tissue; H\&M exp, high and medium expression; Low exp, low expression; Null exp, undetectable expression; NCT, non-tumour cervical tissue; UTR, untranslated region.

sequencing data confirmed that the 5 non-SLC5A8-expressing CC cell lines (HeLa, CaLo, SiHa, CaSki and C-33A) exhibit aberrant methylated epigenotypes, in sharp contrast to the unmethylated profiles of the NCTs. In spite of the different patterns of CGI methylation in the CC cell lines, a common region of almost fully methylated $\mathrm{CpG}$ sites was observed among all the sequenced alleles of the cell lines (sites 13-32; Fig. 2B).

Aggregated methylation maps of the clones were used to weigh the relative contribution of each $\mathrm{CpG}$ site to the methylation status and to calculate the global methylation percentages of the samples. This analysis revealed that the NCTs exhibited a global methylation level $<7 \%$; whereas HPV16-positive SiHa and CaSki cells displayed the highest methylation levels $(>80 \%)$, followed by HPV18-positive $\mathrm{HeLa}$ and CaLo cells (>65\%); and HPV-negative C-33A cells $(62 \%)$ (Fig. S2). These results indicate an association between SLC58A transcriptional repression and the aberrant methylation status of the analysed 379-bp region.
Inhibition of DNA methylation and histone deacetylation contribute to the upregulation of SLC5A8. Since the epigenetic silencing by DNA methylation is often accompanied by repressive histone modifications, the effects of hindering DNA methylation and histone deacetylation on the expression of SLC5A8 were investigated. Therefore, the CC cells were treated with DNMT inhibitor 5-azadC and/or HDAC inhibitors TSA and pyruvate. Following the drug treatments, RT-PCR was performed to determine whether SLC5A8 was expressed. Preliminary experiments were performed using $10 \mu \mathrm{M} \mathrm{5-azadC}$ treatment for all the cell lines (data not shown). However, in some cell lines, a higher concentration was required to observe an effect on SLC5A8 expression.

As demonstrated in the panels of Fig. 3, exposure to 5-azadC alone was sufficient to restore the expression of SLC5A8 in the HeLa, SiHa and CaSki cells (Fig. 3A-C). On the other hand, TSA exposure did not modify the silenced state of this gene in any of the cell lines. Whereas the separate individual treatments failed to induce the transcription of SLC5A8 in the 
Table II. Clinical data of patients with cervical cancer.

\begin{tabular}{|c|c|c|c|}
\hline $\begin{array}{l}\text { Patient } \\
\text { ID }\end{array}$ & $\begin{array}{l}\text { HPV } \\
\text { type }\end{array}$ & $\begin{array}{l}\text { FIGO } \\
\text { stage }\end{array}$ & Histological classification \\
\hline 64 & 16 & IIIB & Invasive, moderately differentiated epidermoid carcinoma \\
\hline 66 & 18 & IIB & Invasive, moderately differentiated epidermoid carcinoma \\
\hline 68 & 18 & IIB & Invasive, moderately differentiated epidermoid carcinoma \\
\hline 71 & 33 & IIB & Invasive, poorly differentiated epidermoid carcinoma \\
\hline 72 & 18 & IIB & Invasive, moderately differentiated epidermoid carcinoma \\
\hline 73 & $58 / 52$ & IIB & Invasive, poorly differentiated epidermoid carcinoma \\
\hline 75 & $58 / 52$ & IIB & Invasive, moderately differentiated epidermoid carcinoma \\
\hline 77 & 68 & ND & ND \\
\hline 78 & 51 & IIB & Moderately differentiated epidermoid carcinoma \\
\hline 82 & 59 & IIB & Moderately differentiated epidermoid carcinoma \\
\hline 83 & $45 / 59$ & IIB & Invasive, moderately differentiated epidermoid carcinoma with lymphovascular permeation \\
\hline 84 & 45 & IIB & Invasive, moderately differentiated adenocarcinoma \\
\hline 85 & 16 & IB2 & Invasive, moderately differentiated epidermoid carcinoma with lymphovascular permeation \\
\hline 86 & $45 / 51$ & IIB & Invasive, poorly differentiated epidermoid carcinoma with lymphovascular permeation \\
\hline 87 & 59 & IIIB & Epidermoid carcinoma with exophytic growth \\
\hline 88 & $45 / 59$ & IIIB & Invasive, moderately differentiated epidermoid carcinoma with lymphovascular permeation \\
\hline 89 & ND & IIIB & Invasive, moderately differentiated epidermoid carcinoma \\
\hline 92 & $45 / 59$ & IIB & Invasive, poorly differentiated epidermoid carcinoma \\
\hline 93 & 45 & IB2 & Invasive, moderately differentiated epidermoid carcinoma \\
\hline 94 & 16 & IIIA & Invasive, moderately differentiated epidermoid carcinoma with lymphovascular permeation \\
\hline 96 & $58 / 52 / 45$ & IIB & Invasive, moderately differentiated epidermoid carcinoma \\
\hline 97 & 16 & IB2 & Invasive, moderately differentiated epidermoid carcinoma \\
\hline 98 & 18 & IIB & Invasive, moderately differentiated adenocarcinoma \\
\hline 99 & 16 & IIA & Poorly differentiated epidermoid carcinoma \\
\hline 101 & 16 & IIB & Moderately differentiated epidermoid carcinoma \\
\hline 104 & $16 / 31$ & IIB & Moderately differentiated epidermoid carcinoma \\
\hline 106 & 16 & IIB & Invasive, moderately differentiated epidermoid carcinoma \\
\hline 107 & $35 / 42 / 43$ & IIB & Invasive, moderately differentiated epidermoid carcinoma, with exophytic pattern \\
\hline 108 & ND & IIB & Invasive, moderately differentiated epidermoid carcinoma \\
\hline 109 & ND & IIB & Invasive, moderately differentiated epidermoid carcinoma \\
\hline
\end{tabular}

HPV, human papillomavirus; FIGO, International Federation of Gynaecology and Obstetrics; ND, not determined.

CaLo cells, the combination of 5-azadC and TSA displayed a synergistic effect in the induction of its expression (Fig. 3D). In contrast, none of the treatments led to SLC5A8 detection in the C-33A cells (Fig. 3E). Similar effects were observed in the presence of pyruvate. The expression of SLC5A8 was reactivated in the $\mathrm{HeLa}$, $\mathrm{SiHa}$ and CaSki cells by 5 -azadC and in the CaLo cells by 5-azadC/TSA (Fig. 3F-I); although there was even a reactivation of SLC5A8 in the SiHa cells following exposure to TSA (Fig. 3G), and in the C-33A cells following exposure to 5-azadC/TSA (Fig. 3J). These results suggest that various factors contribute to the epigenetic silencing of the SLC5A8 gene in the CC cell lines, since this repression is reversed upon exposure to inhibitors of DNA methylation and histone deacetylation, which seem to be more effective in combination.

SLC5A8 gene is frequently repressed and aberrantly methylated in cervical TTs. The present study further aimed to analyse whether SLC5A8 repression is a frequent event in clinical CC specimens. For this purpose, total DNA was extracted from a panel of 30 TTs from patients with $\mathrm{CC}$ in order to characterize their distinct HR-HPV genotypes, tumour stages and histological conditions (Table II). Among the different HPV genotypes, types 16 (26.7\%) and $45(23.3 \%)$ were the most prevalent, followed by the $59(16.7 \%)$ and $18(13.3 \%)$. In addition, the coinfection prevalence $(30 \%)$ was lower than monoinfection $(60 \%)$ among the samples. The majority of the samples were classified as FIGO stage IIB.

Total RNA was isolated from the TTs, and following RNA quality assessment, SLC5A8 expression was examined in 29 samples using RT-PCR (Fig. 4). Differential SLC5A8 gene expression was observed among the TTs. Samples expressing SLC5A8 were significantly different to the samples with a repressed SLC5A8 expression $(\mathrm{P}<0.0001)$. Overall, 10 of the TTs $(34.5 \%)$ have medium and high levels of SLC5A8 expression. Of the remaining 19 samples (65.5\%), 8 displayed downregulated SLC5A8 expression (27.6\%) and SLC5A8 was completely repressed in 11 TTs $(37.9 \%)$.

Subsequently, detailed DNA methylation analyses were performed in 27 of these clinical samples with sufficient DNA quantity, to test whether SLC5A8 downregulation is associated with aberrant methylation of the same region analysed in the 
CC cell lines. Hence, genomic DNA extracts from the TTs were used for bisulphite treatment and sequencing analysis, while 5 additional NCTs were examined as reference samples. The profiles of the individual alleles are demonstrated in Fig. S3, where the NCTs are presented in one cluster and the TTs are grouped into three clusters, depending on their level of SLC5A8 expression: Medium/high, low and null. Considering these sequencing profiles, the density of $\mathrm{mCpG}$ sites in the SLC5A8 CGI was calculated for each sample. The derived data confirmed a low density of $\mathrm{mCpG}$ sites in the NCTs. Out of 27 TTs, 12 exhibited $<40 \% \mathrm{mCpG}$ density, and are therefore considered unmethylated tumours, and the remaining 15 TTs are regarded as methylated tumours (Fig. 5A). In addition, a Kruskal-Wallis test was used to compare the average methylation values of each cluster, demonstrating statistically significant differences between the cluster of TTs with null SLC5A8 expression and the TTs with high/medium SLC5A8 expression $(\mathrm{P}<0.01)$ and the NCTs $(\mathrm{P}<0.001)$.

The aggregated profiles of the cervical TTs reflected the increase of M-SLC5A8 epigenotypes as the expression of the transporter decreased in the clusters (Fig. 5B). The majority of the CpG sites in the cluster of TTs with high or medium levels of SLC5A8 expression displayed low levels of methylation, similarly to the NCTs. The global methylation level of this TT cluster was $\sim 25 \%$. The aggregated profile of the TTs with low SLC5A8 expression reflected the mixture of unmethylated and methylated alleles, where the increase of the $\mathrm{mCpG}$ sites contributed to a global methylation value of $37 \%$. On the other hand, the cluster of TTs that did not express SLC5A8 exhibited a majority of heavily methylated $\mathrm{CpG}$ sites, with the highest global methylation level (74\%). In general, these findings suggest that SLC5A8 hypermethylation is a frequent event that not only takes place in the $\mathrm{CC}$ cell lines, but is also present in cervical tumours, and may be involved in its silencing.

\section{Discussion}

The present study investigated SLC5A8 expression and its potential epigenetic silencing in $\mathrm{CC}$, considering that SLC5A8 is a component of a broad underexplored family of transmembrane transporters with high disease relevance (23), and the particular nature of this viral-induced cancer. Furthermore, SLC5A8 silencing has been described in a number of tumour types, including colon, pancreas, brain and breast cancer, as well as acute myeloid leukemia (9-11), and its downregulation may be required for the metabolic reprogramming in transformed cells, an emerging hallmark of cancer (15).

The present results suggest that SLC5A8 transcriptional inactivation is a common event in CC. It was first demonstrated that SLC5A8 is expressed in NCTs, which is in agreement with the transcript expression evidence reported recently in the Nextprot database (https://www.nextprot.org; accession no. NX_Q8N695). On the other hand, the transporter was undetected in $100 \%$ of the CC cell lines analysed and heterogeneously expressed in TTs, where $65.5 \%$ of the samples exhibited completely suppressed or downregulated expression. This percentage is higher than that reported in similar studies, including one performed on lung cancer, with decreased or lost expression of SLC5A8 in 39\% of TTs (24), or one on prostate cancer, where the gene was downregulated in $60 \%$ of TTs $(25)$.

CGIs in the promoter regions of several genes, often extending into the 5'-UTRs and downstream into the coding region, are particularly susceptible to abnormal gains of $\mathrm{CpG}$ methylation leading to their silencing in a cancer type-specific way (26). In the CC cell lines, MS-PCR screening allowed the detection of $\mathrm{mCpG}$ sites within the CGI identified in exon 1 of SLC5A8. MS-PCR is a rapid and cost-effective tool to investigate the DNA methylation status of CpG sites (27), but despite its high sensitivity and specificity (28), it can assess the methylation status of only a small number of CpGs; consequently, it cannot accurately reflect the level of DNA methylation along a target region. In addition, there is a risk of false-positive results due to mispriming $(27,29)$. Therefore, through bisulphite-sequencing, individual DNA methylation maps of the transporter CGI were generated, and their methylation levels were characterized. The unmethylated profiles of the NCTs contrasted with the methylated profiles of the $5 \mathrm{CC}$ cell lines, which yielded similar epigenotypes depending on the type of HPV (18, 16 or negative). The methylation status of a 'mini' CGI (<200 bp) upstream of the TSS was further examined (data not shown), since it is situated in a region described by Zhang et al (30) as essential for the promoter activity of SLC5A8 in 293T cells. However, non-homogeneous patterns or coincidentally methylated $\mathrm{CpG}$ sites in this region were observed among the cell lines. These results imply that methylation over the CGI in the first exon region may have a higher impact on the regulation of SLC5A8 transcriptional expression, as observed for the first exon of the $\alpha 2$ (I) collagen gene (31). This is also consistent with the findings of Brenet et al (32) regarding the closer linkage of gene transcriptional silencing with DNA methylation downstream of their TSSs, within the first exon, than with methylation in the upstream promoter regions, which is more variable and less strict.

The silencing associated with DNA hypermethylation may be a product of either the direct inhibition of transcription factor binding to specific $\mathrm{CpG}$ dinucleotides or mediated by the attraction of methyl-binding domain proteins that, in turn, hinder the access of regulatory elements to the DNA and restrain transcription (33). Whereas certain differences were observed among the SLC5A8 methylation patterns of the CC cell lines, one block of CpG sites in the 5'-UTR (sites 13-32; position +245 to +356 ) emerged as being almost uniformly methylated. Consequently, it is speculated that the absence of SLC5A8 expression is largely influenced by dense methylation in this block of $20 \mathrm{CpG}$ dinucleotides. Along these CpGs, a computational prediction using the Genomatix software (https://genomatix.de/) identified the consensus binding sites for the methylation-sensitive transcription factor E2F and transcriptional repressor CTCF $(34,35)$; however, further experiments are required to determine the role of these transcription factors in the regulation of SLC5A8 expression.

Clinical cervical TT specimens are mixtures of various cell types: Cancer cells, adjacent normal cells, stromal cells and infiltrating cells. Hence, the bisulphite-sequencing of these samples outlined more diverse epigenotypes of SLC5A8 CGI than those of the cell lines, ranging from unmethylated to completely methylated profiles. The trend in the TTs expressing SLC5A8 was to exhibit unmethylated profiles. Nearly all the 
non-SLC5A8 expressing TT profiles harboured a high density of methylation, resembling those of the $\mathrm{CC}$ cell lines, and suggesting that methylation of SLC5A8 is predominantly biallelic. The tumours with low levels of SLC5A8 expression featured larger variations in their profiles and may represent the transition from an active unmethylated state to an inactive methylated state, as previously demonstrated in the development of methylation of the p16 tumour suppressor gene, via a 'seeding' of methylation in a subset of $\mathrm{CpG}$ sites (36). A subsequent expansion of this epigenetic mark to adjacent sites occurs, until the hypermethylation level required for the stability of transcriptional repression is reached (37). Notably, a small number of cervical TT samples with downregulated SLC5A8 expression were not methylated in the transporter sequence, suggesting alternative genetic or epigenetic mechanisms not yet identified, e.g. microRNAs (miRs) targeting SLC5A8. However, for the majority of the $\mathrm{CC}$ samples, a higher presence of M-SLC5A8 alleles was associated with the suppression of the gene expression.

It is considered that $\mathrm{CpG}$-rich promoters are negatively regulated by DNA methylation, but histone deacetylation also exhibits a crucial participation in methylation-induced gene silencing. Consistent with this idea, a demethylating agent (5-azadC) and HDAC inhibitors (TSA and pyruvate) were used to determine whether DNA methylation, histone modifications or their combination influenced SLC5A8 repression in $\mathrm{CC}$ cell lines. The difference in the effectiveness of these treatments may be indicative of the hierarchy of the two epigenetic mechanisms in dysregulating this transporter. 5-azadC alone was sufficient to restore SLC5A8 mRNA expression in $\mathrm{HeLa}$, SiHa and CaSki cells, which displayed the most densely methylated profiles. This consistency between the inhibition of methylation and the reactivation of SLC5A8 expression indicates that DNA methylation functions as the main epigenetic lock of the SLC5A8 silenced state in these cells. Conversely, in the CaLo cells, SLC5A8 repression was only reversed by the combination of 5-azadC and HDAC inhibitors. This reveals the active contribution of histone deacetylation in the silencing process of SLC5A8, compensating for the lesser DNA methylation status in these cells. Notably, in the C-33A cells, the only tested cell line containing mutant p53 (R273H), M-SLC5A8 was scarcely modified following exposure to 5 -azadC, alone or combined with TSA or pyruvate. According to these results, HPV-CC cells were more sensitive to 5-azadC than $\mathrm{C}-33 \mathrm{~A}$ cells.

In the absence of 5-azadC, the impact of TSA and pyruvate suggests that they may primarily require a partially unmethylated SLC5A8 CGI in order to be able to exert an effect on transcriptional activation. An apparent synergy was observed among pyruvate, 5-azadC and/or TSA, which in combination increased the recovery of SLC5A8 expression in $\mathrm{SiHa}$ and in C-33A cells. This synergism was confirmed by performing quantitative RT-PCR in HeLa cells (data not shown). Thorough investigations are required to analyse potential use of pyruvate as a cancer therapeutic agent, considering that it predominantly inhibits class I HDACs, which are overexpressed in cancer and their inhibition often leads to selective apoptosis and growth arrest of tumour cells (38). Furthermore, since pyruvate is a high-affinity SLC5A8 substrate, its SLC5A8-mediated entry represents an alternative for the reversion of the altered metabolic profile (Warburg effect) observed in cancer cells, which maintain low levels of pyruvate through its conversion into lactate, in order to prevent HDAC inhibition and apoptosis induction $(13,15)$.

A question that arises from the present study is the identification of other mechanisms that may be promoting the effects of 5-azadC on the reactivation of SLC5A8. It is hypothesised that 5-azadC promotes SLC5A8 demethylation by direct interference with DNMTs, particularly with DNMT1, which has been identified as responsible for the epigenetic silencing of SLC5A8 in colon and breast cancer studies $(11,12)$. It is also plausible to consider that DNMT1 serves a dominant role in the epigenetic silencing of SLC5A8 in CC, since HPV-encoded E6 and E7 induce its expression (17). Therefore, the 5-azadC-induced SLC5A8 reactivation may be fostered by a complementary mechanism that involves the inhibition of the E6 and E7 oncogene expression in HPV-positive CC cell lines (39). As for the latter, previous studies indicated that miR-375 is often silenced by promoter hypermethylation in HPV-transformed CC cell lines, CIN3 and squamous CC cells (40), and Stich et al (41) recently reported that the restoration of its expression following 5-azadC treatment was linked to the decrease in E6 and E7 transcripts. A decrease in E6 expression contributes to an increase in wild-type p53 $(39,41)$ and a decrease in the global 5'-methylcytosines levels, since wild-type p53 binds to transcription factor SP1 and chromatin-remodelling proteins to repress the DNMT1 promoter activity (42). On the contrary, in C-33A cells, the R273H p53 mutant cannot repress the promoter of DNMT1 as strongly (42), exerting a minor impact in demethylation. Therefore, aberrant DNA methylation and the R273H p53 mutant may contribute to maintaining the SLC5A8 silenced state.

Throughout the present study, the results highlight the role of DNA hypermethylation as a key epigenetic regulator of SLC5A8 gene transcription in CC cell lines and in primary cervical tumours; likewise, histone deacetylation takes part in the regulation of the transporter gene, but the contribution of the two mechanisms to its silencing vary depending on the cell line. In HPV-CC, 5-azadC is particularly beneficial since it upregulates SLC5A8 expression and, in parallel, may downregulate E6 and E7 expression. As for other tumour types, no reports exist confirming that somatic SLC5A8 mutations are a frequent event in CC, whereas the hypermethylated behaviour of this gene coincides with that previously observed in different cancer types, including colon cancer, acute myeloid leukemia, glioma and lung cancer $(8,9,24,43)$. A previous study identified that upregulation of SLC5A8 for cancer therapy, using DNA methylation inhibitors, could increase the response to other anticancer drugs that use the transporter for entry into tumour cells, including dichloroacetate, which is capable of inducing tumour-cell selective apoptosis, resulting in the suppression of tumour growth (44). These observations suggest that the restoration of SLC5A8 expression may help therapy efforts in CC. Furthermore, preliminary results suggest its potential function as a tumour suppressor in CC, but additional studies are required to validate the possible implication of SLC5A8 in CC development, as a biomarker or therapeutic target in this malignancy. 


\section{Acknowledgements}

The authors thank Ms Patricia De La Torre, Department of Immunology, Biomedical Research Institute, National Autonomous University of Mexico, Mexico City, Mexico, for sequencing the PCR products of the bisulphite-treated DNA.

\section{Funding}

This study was supported by the Mexican Council of Science and Technology (grant nos. 377967 CVU to JHJ; 168896 and 261875 to JDC; and 236767 to PG). The authors also acknowledge the contribution of the Centre for Research and Advanced Studies of the National Polytechnic Institute (grant no. 157593 to $P G)$.

\section{Availability of data and materials}

The datasets used and/or analysed during the current study are available from the corresponding author on reasonable request.

\section{Authors' contributions}

JHJ, PG and JDC conceived and designed the experiments and analysed the data. JHJ and OVS performed the experiments. DCL provided the tissues from patients and performed the clinical data diagnostics. JFR and CPP performed the RNA/DNA extraction from the patient samples. PG, JDC, CLC and LAH contributed with materials, reagents and equipment, and in the analyses and interpretation of data. JHJ, JDC and PG contributed in the manuscript writing. All authors have read and approved the final version of the manuscript.

\section{Ethics approval and consent to participate}

Ethical approval was obtained from the Institutional Ethics and Scientific Board Committees at the National Institute of Cancer of Mexico (CEI/1146/16). All procedures involving human participants were performed in accordance with the ethical standards of these committees and the 1964 Helsinki declaration and its later amendments or comparable ethical standards. Informed consent was obtained from all individual participants included in the study.

\section{Patient consent for publication}

Not applicable.

\section{Competing interests}

The authors declare that they have no competing interests.

\section{References}

1. Bray F, Ferlay J, Soerjomataram I, Siegel RL, Torre LA and Jemal A: Global cancer statistics 2018: GLOBOCAN estimates of incidence and mortality worldwide for 36 cancers in 185 countries. CA Cancer J Clin 68: 394-424, 2018.

2. Subramanya D and Grivas PD: HPV and cervical cancer: Updates on an established relationship. Postgrad Med 120: 7-13, 2008.

3. Fang J, Zhang H and Jin S: Epigenetics and cervical cancer: From pathogenesis to therapy. Tumour Biol 35: 5083-5093, 2014
4. Li E and Zhang Y: DNA methylation in mammals. Cold Spring Harb Perspect Biol 6: a019133, 2014.

5. Portela A and Esteller M: Epigenetic modifications and human disease. Nat Biotechnol 28: 1057-1068, 2010.

6. Kazanets A, Shorstova T, Hilmi K, Marques M and Witcher M: Epigenetic silencing of tumor suppressor genes: Paradigms, puzzles, and potential. Biochim Biophys Acta 1865: 275-288, 2016.

7. Bhutia YD, Babu E, Ramachandran S, Yang S, Thangaraju M and Ganapathy V: SLC transporters as a novel class of tumour suppressors: Identity, function and molecular mechanisms. Biochem J 473: 1113-1124, 2016.

8. Li H, Myeroff L, Smiraglia D, Romero MF, Pretlow TP, Kasturi L, Lutterbaugh J, Rerko RM, Casey G, Issa JP, et al: SLC5A8, a sodium transporter, is a tumor suppressor gene silenced by methylation in human colon aberrant crypt foci and cancers. Proc Natl Acad Sci USA 100: 8412-8417, 2003.

9. Whitman SP, Hackanson B, Liyanarachchi S, Liu S, Rush LJ, Maharry K, Margeson D, Davuluri R, Wen J, Witte T, et al: DNA hypermethylation and epigenetic silencing of the tumor suppressor gene, SLC5A8, in acute myeloid leukemia with the MLL partial tandem duplication. Blood 112: 2013-2016, 2008.

10. Ganapathy V, Thangaraju M, Gopal E, Martin PM, Itagaki S, Miyauchi S and Prasad PD: Sodium-coupled monocarboxylate transporters in normal tissues and in cancer. AAPS J 10: 193-199, 2008.

11. Elangovan S, Pathania R, Ramachandran S, Ananth S, Padia RN, Srinivas SR, Babu E, Hawthorn L, Schoenlein PV, Boettger T, et al: Molecular mechanism of SLC5A8 inactivation in breast cancer. Mol Cell Biol 33: 3920-3935, 2013.

12. Thangaraju M, Cresci G, Itagaki S, Mellinger J, Browning DD, Berger FG, Prasad PD and Ganapathy V: Sodium-coupled transport of the short chain fatty acid butyrate by SLC5A8 and its relevance to colon cancer. J Gastrointest Surg 12: 1773-1782, 2008.

13. Thangaraju M, Gopal E, Martin PM, Ananth S, Smith SB, Prasad PD, Sterneck E and Ganapathy V: SLC5A8 triggers tumor cell apoptosis through pyruvate-dependent inhibition of histone deacetylases. Cancer Res 66: 11560-11564, 2006.

14. Thangaraju M, Carswell KN, Prasad PD and Ganapathy V: Colon cancer cells maintain low levels of pyruvate to avoid cell death caused by inhibition of HDAC1/HDAC3. Biochem J 417: 379-389, 2009.

15. Ganapathy V, Thangaraju M and Prasad PD: Nutrient transporters in cancer: Relevance to Warburg hypothesis and beyond. Pharmacol Ther 121: 29-40, 2009.

16. Durzynska J, Lesniewicz K and Poreba E: Human papillomaviruses in epigenetic regulations. Mutat Res Rev Mutat Res 772: 36-50, 2017.

17. Sen P, Ganguly P and Ganguly N: Modulation of DNA methylation by human papillomavirus E6 and E7 oncoproteins in cervical cancer. Oncol Lett 15: 11-22, 2018.

18. Hirschowitz L, Nucci M and Zaino RJ: Problematic issues in the staging of endometrial, cervical and vulval carcinomas. Histopathology 62: 176-202, 2013.

19. Bhatla N, Aoki D, Sharma DN and Sankaranarayanan R: Cancer of the cervix uteri. Int J Gynaecol Obstet 143 (Suppl 2): 22-36, 2018.

20. Sotlar K, Diemer D, Dethleffs A, Hack Y, Stubner A, Vollmer N, Menton S, Menton M, Dietz K, Wallwiener D, et al: Detection and typing of human papillomavirus by e6 nested multiplex PCR. J Clin Microbiol 42: 3176-3184, 2004.

21. Bock C, Reither S, Mikeska T,Paulsen M, Walter J and LengauerT: BiQ Analyzer: Visualization and quality control for DNA methylation data from bisulfite sequencing. Bioinformatics 21: 4067-4068, 2005.

22. Skinner MK: Epigenetics: A reference manual edited by Jeffrey M. Craig and Nicholas C. Wong. Q Rev Biol 88: 351-352, 2013.

23. César-Razquin A, Snijder B, Frappier-Brinton T, Isserlin R, Gyimesi G, Bai X, Reithmeier RA, Hepworth D, Hediger MA, Edwards AM, et al: A call for systematic research on solute carriers. Cell 162: 478-487, 2015.

24. Park JY, Kim D, Yang M, Park HY, Lee SH, Rincon M, Kreahling J, Plass C, Smiraglia DJ, Tockman MS, et al: Gene silencing of SLC5A8 identified by genome-wide methylation profiling in lung cancer. Lung Cancer 79: 198-204, 2013.

25. Lin HY, Park HY, Radlein S, Mahajan NP, Sellers TA, Zachariah B, Pow-Sang J, Coppola D, Ganapathy V and Park JY: Protein expressions and genetic variations of SLC5A8 in prostate cancer risk and aggressiveness. Urology 78: 971. e1-971.e9, 2011. 
26. Yang HJ: Aberrant DNA methylation in cervical carcinogenesis. Chin J Cancer 32: 42-48, 2013.

27. Huang Z, Bassil CF and Murphy SK: Methylation-specific PCR. Methods Mol Biol 1049: 75-82, 2013.

28. Herman JG, Graff JR, Myöhänen S, Nelkin BD and Baylin SB: Methylation-specific PCR: A novel PCR assay for methylation status of CpG islands. Proc Natl Acad Sci USA 93: 9821-9826, 1996.

29. Yamada $\mathrm{N}$ and Yonezawa S: Understanding epigenetic status: DNA methylation and cancer. J Cancer Biol Res 1: 1008, 2013

30. Zhang Y, Bao YL, Wu Y, Yu CL, Sun Y and Li YX: Identification and characterization of the human SLC5A8 gene promoter. Cancer Genet Cytogenet 196: 124-132, 2010.

31. Sengupta PK and Smith BD: Methylation in the initiation region of the first exon suppresses collagen pro- $\alpha 2$ (I) gene transcription. Biochim Biophys Acta 1443: 75-89, 1998.

32. Brenet F, Moh M, Funk P, Feierstein E, Viale AJ, Socci ND and Scandura JM: DNA methylation of the first exon is tightly linked to transcriptional silencing. PLoS One 6: e14524, 2011.

33. Deaton AM and Bird A: CpG islands and the regulation of transcription. Genes Dev 25: 1010-1022, 2011.

34. Baron B: Breaking the silence: The interplay between transcription factors and DNA methylation. In: Methylation-From DNA, RNA and Histones to Diseases and Treatment. IntechOpen Limited, London, 2012.

35. Chen YJ, Chen YL, Chang Y, Wu CC, Ko YC, Tsao SW, Chen JY and Lin SF: Epstein-Barr Virus Rta-Mediated Accumulation of DNA Methylation Interferes with CTCF Binding in both Host and Viral Genomes. J Virol 91: e00736-e17, 2017.

36. Wong DJ, Foster SA, Galloway DA and Reid BJ: Progressive region-specific de novo methylation of the p16 $\mathrm{CpG}$ island in primary human mammary epithelial cell strains during escape from M(0) growth arrest. Mol Cell Biol 19: 5642-5651, 1999.

37. Turker MS: Gene silencing in mammalian cells and the spread of DNA methylation. Oncogene 21: 5388-5393, 2002.
38. Delcuve GP, Khan DH and Davie JR: Targeting class I histone deacetylases in cancer therapy. Expert Opin Ther Targets 17 29-41, 2013.

39. Chen GD, Qian DY, Li ZG, Fan GY, You KL and Wu YL: Down-regulation of p16 and MGMT promotes the anti-proliferative and pro-apoptotic effects of 5-Aza-dC and radiation on cervical cancer cells. Cell Biochem Funct 35: 488-496, 2017.

40. Wilting SM, Verlaat W, Jaspers A, Makazaji NA, Agami R, Meijer CJ,Snijders PJ and Steenbergen RD: Methylation-mediated transcriptional repression of microRNAs during cervical carcinogenesis. Epigenetics 8: 220-228, 2013.

41. Stich M, Ganss L, Puschhof J, Prigge ES, Reuschenbach M, Guiterrez A, Vinokurova S and von Knebel Doeberitz M: 5-aza-2'-deoxycytidine (DAC) treatment downregulates the HPV E6 and E7 oncogene expression and blocks neoplastic growth of HPV-associated cancer cells. Oncotarget 8: 52104-52117, 2016.

42. Lin RK, Wu CY, Chang JW, Juan LJ, Hsu HS, Chen CY, Lu YY, Tang YA, Yang YC, Yang PC, et al: Dysregulation of p53/Sp1 control leads to DNA methyltransferase-1 overexpression in lung cancer. Cancer Res 70: 5807-5817, 2010.

43. Jiang Z, Li XG, Hu J, Lu DR, Zhou W, Jiang YQ and Li CY: The methylation and mRNA expression of SLC5A8 and TMS1/ASC genes in human glioma. Zhonghua Yi Xue Za Zhi 87: 292-297, 2007 (In Chinese).

44. Michelakis ED, Webster L and Mackey JR: Dichloroacetate (DCA) as a potential metabolic-targeting therapy for cancer. Br J Cancer 99: 989-994, 2008.

This work is licensed under a Creative Commons Attribution-NonCommercial-NoDerivatives 4.0 International (CC BY-NC-ND 4.0) License. 